\title{
Ensino de Filosofia em espaços não formais: notas de uma experiência
}

\section{Philosophy teaching in non-formal spaces: notes of an experience}

\author{
Silmara Cristiane Pinto* \\ Universidade Estadual Paulista Júlio de \\ Mesquita Filho
}

Sara Morais da Rosa**

Universidade Estadual Paulista Júlio de Mesquita Filho

Rodrigo Pelloso Gelamo***

Universidade Estadual Paulista Júlio de Mesquita Filho

\author{
Amanda Veloso Garcia**** \\ Universidade Estadual Paulista Júlio de \\ Mesquita Filho \\ Manoela Paiva Menezes***** \\ Universidade Estadual Paulista Júlio de \\ Mesquita Filho
}

Resumo Este artigo tem como objetivo apresentar os resultados do projeto de extensão "Ensino de filosofia em espaços não formais", explicitando tanto os processos de sua execução em termos práticos quanto seus desdobramentos filosóficos. A ideia geral do projeto era criar um espaço dedicado às possibilidades de experiência com o filosofar, diferente daquele estabelecido em ambientes formais (instituição escolar). Devido às experiências anteriores que tivemos com o ensino de filosofia nas formalidades institucionais, procuramos transbordar esses espaços, convertendo o ensino tradicional em uma dimensão dialógica de aprendizagem e de criação de pensamento. Em síntese, a escrita deste texto permite que exploremos algumas implicações daquilo que projetamos e que doravante vivenciamos: nossa própria construção de sentido acerca do ensinar e do aprender filosofia e, sobretudo, do que significa pensar filosoficamente.

PALAVRAS-ChaVE: Ensino de filosofia; Signos; Experiência filosófica.

Abstract This article presents the findings of the university extension project "Philosophy teaching in non-formal spaces" and explains both the process of its implementation in practical terms and its philosophical developments. The general idea was to create a space to offer an experience at philosophizing, different from the one established in formal settings (school). Due to previous experiences regarding Philosophy teaching in institutional formalities, we tried to overflow the limits of these spaces, by converting the classical teaching into a dialogical dimension of learning and creating new spaces for thinking. In summary, this article has allowed us to explore some implications about what we have planned and henceforth what we have been experiencing: our own construction of meaning about teaching and learning Philosophy, especially of what it means to think philosophically.

KEYWORDS: Philosophy teaching; Signs; Philosophical experience. 


\section{Introdução e problemática}

O presente artigo é inspirado nos resultados de um projeto intitulado "Ensino de Filosofia em Espaços não formais", desenvolvido no período de dois anos em uma instituição que assiste adolescentes em conflito com a lei. $\mathrm{O}$ projeto tinha por objetivo promover com seus participantes uma experiência de pensamento filosófica que não fosse marcada pelas diretrizes de ensino formal, mas que, de algum modo, pudesse nos levar a romper com nossas possibilidades familiares de significação e, assim, instaurar um processo de transvaloração de nossos juízos habituais.

Ao longo de quatro anos de atuação no ambiente escolar, articulamos o projeto "Os Limites do Ensino da Filosofia no Programa São Paulo faz Escola" ao PIBID (Programa Institucional de Bolsa de Iniciação à Docência, ligado à CAPES - Coordenação de Aperfeiçoamento de Pessoal de Nível Superior). O objetivo era investigar as implicações do material didático de apoio ao professor e aos estudantes, oferecido pelo Programa São Paulo Faz Escola, para o ensino de filosofia nas situações de aprendizagem propostas.

A experiência inicial com o trabalho docente levou-nos a identificar limitações circunscritas à disciplina de filosofia no contexto do Ensino Médio e ao material didático oferecido pela Secretaria da Educação do Estado de São Paulo. Embora as essenciais pretensões do sistema escolar incluíssem disciplinar habilidades e desenvolver o pensamento crítico por uma formação integradora, como prescrito na LDB (Lei de Diretrizes e Bases), nos PCN (Parâmetros Curriculares Nacionais), nas OCN (Orientações Curriculares Nacionais) e na Proposta Curricular do Estado de São Paulo, essas mesmas diretrizes mostravam-se bastante distantes daquilo que se apresentava diante de nossos olhos. Há de se reconhecer que tais objetivos são muito difíceis de serem alcançados dentro dos muros da escola, e, de um ponto de vista mais particular, apresentam também a dificuldade em proporcionar o crucial à própria filosofia: o estímulo à experiência de pensamento filosófica e autêntica do aprendiz.

Nesse entremeio, a estrutura institucionalizada do ensino, na qual se impõem a transmissão de conteúdos selecionados, os procedimentos avaliativos e até mesmo as relações interpessoais no desdobrar dos debates e argumentos em sala de aula - tudo com uma temporalidade predeterminada para sua execução - instigou-nos a questionar as condições do ensino de filosofia para além das diretrizes e normatizações que regulam as instituições escolares.

Ora, que diferenças poderiam emergir em nossa relação com o ensino e com a aprendizagem filosófica se nos dispuséssemos a habitar um espaço desprovido dos compromissos formais e do ideal pedagógico de formação? Nesse momento, a experiência no projeto PIBID abriu-nos caminhos para compormos um novo plano, com novos propósitos que se delineariam mais tarde no projeto "Ensino de filosofia em espaços não formais". Isto porque a experiência como aprendizes docentes no ensino formal possibilitou-nos conhecer e vivenciar os processos de ensino no ambiente escolar, onde a transmissão, a memorização e a recognição de informações mostraram ser procedimentos supervalorizados em detrimento da experiência do pensar. 
No âmbito do ensino de filosofia, especificamente, existe um forte apelo a um conteúdo que se limita àquilo que foi pensado pelos filósofos no decurso da história da filosofia. Estabelece-se por objetivo que o aluno tenha acesso a tais conteúdos e, na assimilação e compreensão dos mesmos, possa bem reconhecer as ideias filosóficas apresentadas, as quais posteriormente serão exigidas em exames, provas, concursos e, principalmente, vestibulares. Nesse caso, para que o aluno tenha contato com a gama de conteúdos prescritos pelo currículo educacional, exige-se um domínio da temporalidade da aprendizagem, ou seja, controla-se o tempo da experiência, fundamental ao aprender filosófico, em virtude da demanda de informações a serem transmitidas.

Assim, a transmissão da filosofia teve de ser reduzida à compreensão objetiva de enunciados filosóficos, que, quando muito, atuavam a favor da constituição de recortes sobre os temas e as formas de pensamento presentes na história da filosofia. Esse modelo de ensino restringia a experiência do aprender a uma relação puramente abstrata: "filosofia era coisa dos filósofos" e aprender filosofia, portanto, seria entender corretamente seus pensamentos.

Isso demonstrava uma imagem de filosofia na escola marcada pelo estatuto da abstração, uma configuração do pensamento na qual as ideias funcionam separadamente do "ordinário" da vida; daí a resistência em aprender tudo o que estaria aparentemente distante, tudo o que seria "inútil". Assuntos do campo da Ética ou da Política, por exemplo, ainda que presentes na vida prática, representavam mais conteúdos a serem ensinados pelo professor do que uma problemática viva e atual no cotidiano. Nesse mesmo sentido, a disciplina de filosofia era qualificada algumas vezes, sobretudo no discurso corrente dos alunos, como algo interessante, porém, não necessário; outras vezes, era vista como diferente, mas, ainda assim, indiferente.

Dessa maneira, desmistificar o valor intangível da filosofia, bem como o certo e o errado das formas de pensar e de aprender, constituía-se como um desafio prático na escola, do mesmo modo em que, para nós, manifestava-se como consequência de um problema: o ensino de filosofia como transmissão de informação. Desde então, iniciamos o exercício de problematizar os pressupostos, nos quais se ancoravam os métodos tradicionais de ensinar, bem como suas implicações na pragmática escolar. Segundo Gelamo (2009), o ensino da filosofia que tem sua prática pautada na transmissão de conteúdos abstratos resulta na produção de:

[...] uma imagem distorcida do pensamento filosófico e do filosofar, transmitindo ao aluno não muito mais do que "fórmulas filosóficas" que passam a se constituir em modelos a serem aplicados na resolução de qualquer questão: tal como se utiliza a fórmula matemática para solucionar uma equação cotidiana, as "fórmulas filosóficas" apresentam-se como modelos a se imitar para pensar criticamente as situações com as quais o aluno depara. (GELAMO, 2009, p. 114).

Nessa perspectiva, o ato de aprender, ao invés de ser concebido como uma forma de "constituir e enfrentar os problemas práticos ou especulativos" (DELEUZE, 2006, p. 236), define-se por apreender uma representação que se efetua pela compreensão e assimilação de uma imagem de determinado conteúdo ${ }^{1}$. Nega-se, assim, o acesso aos problemas e às possibilidades de se pensar com o auxílio dos filósofos estudados, ofe- 
recendo-lhes em seu lugar uma solução, silenciando, portanto, o diálogo e o ato de questionar.

No tocante a este modus operandi adotado como referencial de ensino, Jacques Rancière denuncia, em sua obra $O$ mestre ignorante, o paradigma em que se apoia boa parte dos sistemas de ensino, nos quais "A grande tarefa do mestre é transmitir seus conhecimentos aos alunos para elevá-los gradativamente a sua própria ciência" (RANCIÈRE, 2002, p. 16). Doravante, não compete mais ao aprendiz aprender pelo uso de sua própria inteligência; o que lhe cabe é compreender adequadamente o conjunto de saberes que serão transmitidos por seu professor. Admite-se, de antemão, que apenas uma inteligência superior, como a daquele que ensina, poderá reduzir a distância entre a ignorância e o conhecimento, e, assim, assegurar ao aprendiz a progressão de seu saber.

Por consequência, aquele que poderia aprender pelo exercício de sua inteligência, uma vez participante desta lógica de ensino, tornar-se-á refém de um modo de se relacionar com o conhecimento que não lhe é mais próprio, senão mediado pelas explicações e representações de seu professor. Nesse sentido, Rancière destaca que a instrução pode significar dois atos diametralmente opostos: "confirmar uma incapacidade pelo próprio ato que pretende reduzi-la" ou, em contrapartida, "forçar uma capacidade que se ignora ou se denega a se reconhecer e a desenvolver todas as consequências desse reconhecimento." $(2002$, p. 11). No que tange ao primeiro ato, podemos nomear a explicação, e ao segundo, a emancipação. Para sermos rigorosos com o sentido destinado à explicação, devemos observar o que nos diz Rancière:

A explicação não é necessária para socorrer uma incapacidade de compreender. É ao contrário, essa incapacidade, a ficção estruturante da concepção explicadora do mundo. É o explicador que tem necessidade do incapaz, e não o contrário, é ele que constitui o incapaz como tal. Explicar alguma coisa a alguém é, antes de mais nada, demonstrar-lhe que não pode compreendê-la por si só. Antes de ser um ato do pedagogo, a explicação é o mito da pedagogia, a parábola de um mundo dividido em espíritos sábios e espíritos ignorantes, espíritos maduros e imaturos, capazes e incapazes, inteligentes e bobos. O procedimento próprio do explicador consiste nesse duplo gesto inaugural: por um lado, ele decreta o começo absoluto- somente agora tem início o ato de aprender, por outro lado, ele cobre todas as coisas a serem aprendidas desse véu de ignorância que ele próprio se encarrega de retirar." (RANCIÈRE, 2002, p. 19-20).

Ao invés de promover condições de emancipação do aluno com relação à explicação ou ao pensamento do professor sobre o conteúdo filosófico, esse modo de proceder gera um embrutecimento do pensamento e das inteligências, visto que os alunos devem sempre adequar seu modo de pensar à leitura que o professor faz da filosofia e de suas verdades tradicionais, subtraindo, assim, tanto a experiência de pensamento quanto o processo da produção genuína de sentido por parte do aluno.

No interior desta lógica de ensino, o pensamento é tomado como representação de um polo de referência. Gilles Deleuze, em O que é a filosofia? (1997), Lógica do Sentido (1998) e Diferença e Repetição (2006), realiza uma crítica ao uso de imagens de 
pensamento como pressupostos do que significa pensar. Assim, considerar um ensino ancorado em uma imagem de pensamento é entendê-lo como um instrumento de transmissão de uma verdade a ser reproduzida e, por isto, o autor a chama de "imagem dogmática de pensamento".

Para Deleuze (2006), as imagens dogmáticas caracterizam-se por oito postulados que servem de pressupostos para o que significa pensar em filosofia. Em outras palavras, pensar por imagens, no campo da filosofia, não representa nada mais do que se apoiar em pressupostos geralmente ortodoxos, dogmáticos, que, para Deleuze, são pré-filosóficos, morais e comumente considerados naturais ao pensamento.

A própria expressão "todo mundo sabe, ninguém pode negar..." é um exemplo contundente sugerido por Deleuze para demonstrar que nosso pensamento reproduz uma série de pré-conceitos de forma muito habitual que, uma vez fixados na consciência, transformam-se em sentenças cada vez mais categóricas. Essas sentenças se traduzem por imagens que evidenciam o desfavor ao pensamento filosófico, pois cerceiam os significados que damos às coisas, a começar pelo próprio modo como colocamos nossas questões.

Neste domínio, não há pensamento genuíno, mas recognição e reprodução de ideias. $\mathrm{O}$ aspecto representacional forma a imagem dogmática do pensamento que conforma o pensar a "uma imagem que é a do Mesmo e do Semelhante na representação, mas que trai profundamente o que significa pensar" (DELEUZE, 2006, p. 161).

Posto isto, pareceu-nos imperativo procurarmos um lugar de resistência, um modo de escapar a esse registro que pretende conformar o pensar e o filosofar a uma imagem dogmática de pensamento previamente estabelecida, seja pelos currículos, pelos conteúdos ou pela própria inteligência do professor/explicador.

Para fugir desse registro que circunscreve o modo como devemos nos relacionar com o filosófico e que nos impõe não apenas o que deve ser pensado, mas também quais autores devem ser reproduzidos e quais problemas são dignos de nossa atenção, é que decidimos criar o projeto "Ensino de Filosofia em Espaços não formais". Temos por objetivos deslocar os lugares fixos e seguros nos quais o ensino institucionalizado se alicerça, bem como oferecer aos seus participantes um espaço no qual o pensar pudesse emergir em toda sua potência de criação.

Para a realização deste projeto, enviamos a proposta a uma instituição socioeducativa de semiliberdade em nosso município, a fim de convidar os jovens em cumprimento de medida judicial a realizar conosco encontros semanais, que poderiam ocorrer em diferentes espaços desde que marcados por relações desinstitucionalizadas e não formais. Tendo sido aprovado pela diretoria da instituição, fizemos o convite aos adolescentes que se encontravam em regime de internação.

Convidá-los pareceu-nos mais do que justo, já que a participação deles não seria demarcada por uma obrigatoriedade institucional, mas por um livre desejo de participação. Este projeto só faria sentido se pensado, construído e executado com e por estes jovens e não para eles. Não queríamos levar a eles algo que uma equipe ges- 
tora havia decidido em suas reuniões de coordenação, imaginando qual seria a melhor forma de encaminhar questões, de escolher temas etc., mas, ao contrário, pensar em conjunto todas as atividades e tematizações nelas realizadas. Nove jovens atenderam ao convite e passaram a integrar as atividades do projeto.

\section{Plano de composição de trabalho com a filosofia}

No decorrer dos anos de 2012 e 2013, passamos a promover encontros semanais com o grupo que atendeu ao nosso convite. Esses encontros não tinham uma temática pré-estabelecida. Os temas surgiam a partir de conversas e diálogos, acontecimentos e experiências que todos os integrantes partilhavam, a começar por suas (nossas) próprias vivências. Por meio de debates, os conteúdos filosóficos, que poderiam ou não fazer parte do rol dos temas tradicionalmente elencados para o ensino da filosofia no Ensino Médio, emergiam em nossos encontros com muita frequência e potência. Problematizávamos e nos questionávamos no horizonte desses temas e refletíamos sobre as posições adotadas, na tentativa de desenvolver e construir em conjunto um novo modo de olhar para os mesmos problemas.

Buscávamos, com os adolescentes envolvidos no projeto, nos ensaiar no pensamento ${ }^{2}$, na tentativa de filosofar, ou fazer uma filosofia menor ${ }^{3}$ e, assim, experimentar pensar filosoficamente. Esta atividade nos permitiu explorar de modo diferente o problema do ensino de filosofia que, até então, havíamos experimentado apenas no interior da escola pública, dentro dos limites do ensino formal.

Neste contexto, problemas realmente caros aos participantes deste projeto, em especial aos adolescentes em privação de liberdade, tais como violência, livre-arbítrio, propriedade, entre outros, deixariam de ser tratados no âmbito teórico e abstrato, que poucos elos estabelece com aqueles que o vivenciam mais profundamente. Tais questões foram trabalhadas em toda sua potência problemática, visto que a perspectiva desses jovens, geralmente, trazia à baila um conjunto de normas morais próprias que não correspondiam aos paradigmas de todos. Sendo assim, era necessário abandonarmos sempre as imagens dogmáticas prévias e pensarmos os problemas de outros pontos de vista, o que nos exigia outro modo de relação com eles.

Em que pesem a experiência no Ensino Médio e toda afecção em nós produzida, fomos forçados a pensar e a buscar por um lugar outro, no qual a experiência de pensamento pudesse acontecer. Nossa hipótese era a de que uma das grandes limitações do ensino institucionalizado estava no poder que a instituição exercia sobre professores e alunos no processo de ensinar e aprender a filosofia e em uma imagem do que seria ensiná-la e aprendê-la.

Ansiávamos por experimentar exercer uma atividade filosófica em um espaço no qual as figuras do professor, do aluno, dos conteúdos prévios, dos regimes de verdade e das imagens do que significava pensar, pudessem ser deslocadas, para que algo novo emergisse. Buscávamos uma nova relação com a filosofia, quiçá mais plena de sentido, para todos aqueles que, de algum modo, participassem desta experiência e aprendessem filosofia como uma experiência de pensamento e não como a apreensão das representações que o professor enunciava. 
O projeto "Ensino de filosofia em espaços não formais" visava, então, a promover um lugar de resistência, sobretudo face aos arquétipos que sempre reiteramos na escola. A necessidade era reconstruir um sentido para pensar o ensino que fosse diferente daquele dado como transmissão conteudista. Para tanto, era preciso recompor a figura do professor, concebendo-o não mais como detentor e provedor de conhecimentos, e a figura do aluno não como seu receptáculo. Buscávamos, assim, uma relação diferente da institucional e, mais do que isso, um pensamento não institucionalizado. Isso demandava um processo de resistência constante em nosso próprio pensar, que, na maioria das vezes, funciona através de representações determinadas por imagens dogmáticas.

Desfazermo-nos das imagens, então, convertia-se em nos desnudarmos de valores moralizantes tanto em relação à vida comum dos participantes desse projeto, visto que foram sentenciados e considerados menores infratores, quanto de nosso modo de nos relacionarmos filosoficamente com eles, que não mais eram meros receptores de um conteúdo abstrato. Prezávamos por uma participação igualitária em termos de direito ao filosofar, considerando a heterogeneidade e a experiência de cada um em relação às tematizações que eram feitas no e pelo grupo. Uma temática a ser debatida, por exemplo, não era estabelecida por nós de antemão, mas planejada ou pensada em conjunto. Por vezes um conteúdo dessa temática transformava-se em problema e aí se manifestava um jogo de troca, ou seja, pensávamos juntos acerca de um objeto em comum, trocando diferentes experiências de vida e de pensamento.

Foi na construção desse jogo, dessa troca de diálogos e de experiências, portanto, que nossa concepção do filosofar também foi se construindo à medida que aparecia um movimento criativo do pensamento junto à descoberta do próprio ato de pensar. Ao contrário dos hábitos escolares que, em geral, tendem a conformar o aprendiz a uma tradição, moldando-o naquilo que deve pensar, tentávamos estabelecer um convívio filosófico mediante a criatividade do pensamento.

Para Gilles Deleuze (2006), o pensar consiste em um processo de dar sentido àquilo que nos afeta $\mathrm{e}$, desse modo, procurarmos respostas para os problemas que afetam as nossas vidas. Contudo, o autor menciona a existência de pressupostos que atuam como polos de referência para aquilo que pode ser pensado, determinando, por exemplo, quais pensamentos são dignos de nossa atenção. Tal polo de referência estende-se a todos os domínios, incluindo a filosofia. Essa postura procura manter paradigmas da verdade que determinam o que é filosofia, o que é filosofar e, consequentemente, o que é ensinar a filosofia. Dessa forma, aquele que não se adequar a estas concepções não poderá filosofar ou aprender filosofia.

Em contraposição a isso, Deleuze apresenta sua crítica, considerando que o filosofar nasce em decorrência não de ideias impostas por uma tradição filosófica, mas do encontro com signos que afetam o sujeito e o forçam a pensar. Trata-se, portanto, de uma construção de sentido a partir daquilo que afeta o pensamento: 
A construção de sentido não se pauta no paradigma da verdade, pois um modo de existência não pode ser medido pelos critérios de verdadeiro/falso, certo/errado, bom/mau, nobre/vulgar, "não há nunca outro critério senão o teor da existência, a intensificação da vida" (DELEUZE, 1997, p. 97).

O sentido não se filtra pelo critério de verdade, pois o sentido genuíno é "construção" e não "reprodução". Acreditamos que a filosofia é um libertar-se daquilo que é tido como verdadeiro - a imagem dogmática do pensamento - para experimentar um pensar/tornar-se diferente. Desse modo, a filosofia relaciona-se intrinsecamente com a criatividade. O filosofar não se dá na passividade, mas na construção de novas possibilidades e dimensões de pensamento e existência, estabelecendo novas composições de sentido. Destarte, a experiência mostra-se primordial para um pensamento filosófico, uma vez que provoca o pensamento para a construção de sentido.

Diante disso, procurávamos fazer de nossos encontros não um espaço de ensino, mas um lugar de resistência às representações que se pode ter por meio dele; um lugar de profusão de signos; signos filosóficos que nos forçassem a pensar e a nos tornarmos atentos àquilo que, de algum modo, pudesse resultar em um diálogo filosófico. Por isso, o apelo à experiência e a sua narrativa pareceu-nos o caminho mais adequado a se traçar, para que pudéssemos criar um ambiente de partilha de pensamento e não uma relação de transmissão, cuidando para que nossa formação em filosofia não controlasse quaisquer possibilidades de encontro com os signos e tampouco limitasse posicionamentos.

Decidimos, então, experimentar as relações como elas eram, ou seja, procuramos estabelecer um movimento em busca de resistir àquilo que tínhamos aprendido em nossa formação de professor consciencioso (RANCIÈRE, 2002, p. 16) e moralizado pelas imagens dogmáticas do que seria ensinar e como ensinar a filosofia, para entrar no jogo como uma criança, que joga pelo prazer de jogar; que inventa novas relações com os objetos, atribuindo-lhes novos nomes e lhes dando novas funções.

Pensamos que, assim, conseguiríamos deslocar a centralidade do professor na enunciação da verdade sobre os temas em questão e reposicionar tanto as tematizações quanto as verdades sobre elas no espaço comum, onde todos pudessem ter acesso ao objeto e à possibilidade de dizer algo sobre ele. Desse modo, o exercício de análise das temáticas era feito por todos, e isso se tornava um jogo de verificação das possibilidades de pensar e de dizer a verdade sobre as coisas, as temáticas e os problemas, que já não eram do professor, mas de todos aqueles que partilhavam o encontro 4 . Cumpre ressaltar que nosso objetivo não era substituir os valores "tradicionais" por um novo conjunto de normas e verdade filosóficas mais salutares, mas ressaltar aquilo que emergia nas relações.

Desenvolvemos o projeto acreditando que naquele contexto o aprender a filosofar poderia acontecer: já não havia mais regras ou normatizações acerca do ensino, e os problemas filosóficos poderiam estar presentes com toda sua intensidade; afinal já não existiam mais situações hipotéticas ou problemas abstratos, mas, pelo contrário, as questões advinham das experiências dos próprios jovens. 
Porém, apesar de julgarmos que os problemas apresentados, discutidos e pensados por todos nós fossem de cunho filosófico ${ }^{5}$, ainda assim não garantiam que, naquela relação de aprendizado, nós tivéssemos filosofado. Havia algo naquele acontecimento ${ }^{6}$ que ainda nos escapava, pois notávamos que, em algumas circunstâncias, nossas discussões eram frágeis, aparentemente superficiais, ou mesmo efêmeras, haja vista que não se sustentavam por mais de um encontro.

Contudo, em vários outros momentos, notávamos que estávamos problematizando o presente $^{7}$ e as próprias experiências de vida destes jovens com uma intensidade que nos mobilizava na criação de outros modos de relação com o problema levantado, obrigando-nos a sentir e a pensar diferentemente. Mas, novamente, isso nos escapava, num movimento de obstinada negação por parte dos adolescentes, ao que mais uma vez nós respondíamos a partir da seara de um pensamento moralizante.

A pergunta que nos perseguia então era: havíamos filosofado ou não? A resposta que imediatamente nos advém parece negativa. Entretanto, o que havia acontecido naquelas discussões acaloradas, às quais nos dedicávamos com tanta intensidade, mas de cujo debate os participantes decidiam, num ato de resistência à força do problema, depois se abster? Teriam eles, e teríamos nós mesmos, filosofado naqueles momentos? Se sim, o que teria nos levado a filosofar? Que acontecimento teria desencadeado aquelas esporádicas, mas intensas, reflexões e pensamentos?

Estas são questões que ainda não conseguimos responder, mas que continuam a habitar nosso pensamento. O que é possível apontar sobre as vivências deste projeto diz respeito ao modo como os participantes agiam: alguns revertendo questões para nós e afirmando que começavam a perceber o que era filosofia e o que era filosofar; outros incomodando-se com a participação dos colegas e se furtando a respondê-las.

Embora não possamos aferir com certeza que estes jovens tenham filosofado, ou que tenham tido uma experiência de pensamento capaz de criar suas próprias significações, algo nos é certo, tais acontecimentos provocaram em nós grande violência. Estes encontros, fortuitos e invitáveis, arrebataram-nos para além das nossas possibilidades familiares de significação, levando-nos a buscar por novos sentidos para as experiências ali vividas. Sobre este movimento não tínhamos controle algum. E talvez aí, nesse lugar, cujas experiências não é possível narrar, consistia o que há de mais caro ao filosofar.

\section{Considerações finais}

A busca por uma experiência filosófica de pensamento não restrita às instituições de ensino - concebidas, teoricamente, como o lugar de relação com o saber e a produção do conhecimento - posiciona-se à margem do que significa fazer filosofia nesses espaços de formação, a começar pelos pressupostos pertinentes a tal empreitada. Se, por um lado, na escola pretende-se fazer compreender os procedimentos supostamente básicos para a formação do aluno, a hipótese da informalidade de nossas atividades demarca uma inversão relativa às práticas da instituição escolar, ou seja, propõe uma experiência de pensar ou de aprender que reconhece os cultivos do integrante e 
tem por suporte aquilo que trazem no pensamento. Enquanto na escola parte-se do pressuposto da ignorância do aluno, que necessita obter um status de formação, procuramos justamente nos seus saberes e não saberes, nas suas opiniões estabelecidas, a potencialidade para pensar filosoficamente.

Nesse sentido, a sorte de uma aprendizagem tão cara às instituições formais e a nós próprios configura-se nas entrelinhas de um processo que não a sobrepõe como finalidade essencial, mas que deseja estabelecer condições para a reflexão ativa, uma relação singular com os problemas filosóficos. Não querendo traçar objetivos, alimentamos uma espera marcada por diversas intencionalidades, sobretudo pelo devir de um filosofar, entendido, nesse registro, como uma experiência de pensamento desvirtuada das representações.

Se os conteúdos curriculares da filosofia, sua história, seus conceitos tornaram-se distantes nesse tipo de relação, as imagens de uma moralidade ou de critérios universais de verdade mostraram-se presentes no discurso de todos, inclusive daqueles considerados resistentes perante os limites sociais e éticos de convivência. Isso nos demonstrou uma necessidade: perceber que nosso entendimento e nossas ações são, de algum modo, cercadas por representações e regidas, ainda que indiretamente, segundo princípios de identidade.

Deleuze (2006) argumenta que o princípio da identidade supõe pensar por representações. Sugere certa igualdade, comensurabilidade, simetria, retidão do pensamento com o que é estabelecido como verdadeiro, de modo que nossas próprias conviç̧ões sejam constituídas sempre segundo uma identidade absoluta. Com efeito, todo ato que não obedeça à repetição do mesmo, ou seja, que se permite diferenciar-se dos pressupostos representacionais, é considerado negativo, contraditório, deficiente. A diferença, nesse contexto, é colocada sempre no nível de oposição, de antítese, nunca afirmativa de uma autenticidade criativa diferenciante. Segundo Gelamo,

\begin{abstract}
A única possibilidade de diferenciação estaria na relação entre o mesmo e o semelhante e entre o análogo e o oposto. Partindo desses quatro elementos, o pensamento representativo re-apresentaria uma série de conceitos que se diferenciam apenas em grau e não em natureza. Nesse sentido, a representação contribui para que os pressupostos do pensamento se mantenham sempre os mesmos, variando apenas entre os dois extremos: entre aquilo que é análogo e aquilo que é oposto. Além de não garantir o pensamento como diferença em si mesma - uma vez que pensa a diferença sempre em relação a algo do qual o pensado se diferenciou -, o problema da representação está em tratar a diferença como erro ou como falsa representação. (2009, p. 91).
\end{abstract}

Com base nessas considerações, projetamos estabelecer um ambiente de problematização, de inquirição acima de posturas notadamente operadas por imagens representacionais, a fim de desconstruir o mesmo que se repetia no pensamento. Este exercício nos desvelou um mundo de resistências, de negação à alteridade, talvez desconhecido em nós mesmos. Entretanto, pensar e dialogar sobre problemas referentes ao machismo, ao sexismo, às formas mais comuns de preconceito, por exemplo, permitiram o acesso à identificação de que a composição rígida de uma consciência carac- 
teriza-se, de um lado, pela negação do filosofar, mas, que, por isso mesmo, apresenta o ponto problemático de onde surgem, paradoxalmente, os signos para a experiência filosófica.

Nessa perspectiva, um dos diagnósticos provavelmente mais significativos que podemos enunciar como decorrente dessa experiência diz respeito ao modo como a ela reagimos, como the colocamos as questões e como nos relacionamos com ela. A pergunta sobre se filosofamos ou não, ou se criamos possibilidades de filosofar, permanece implícita e não respondida. Porém, para nós, mais importante do que responder a essa questão, foi aquilo que aconteceu nesses encontros: tivemos uma relação singular com aqueles adolescentes e com os problemas que emergiam. Os signos filosóficos neles implicados, ou pelo menos os signos de uma inquietação que ainda sobrevive em nosso pensamento, obrigam-nos a pensar sempre que somos tomados pelos sobressaltos que nos provocam esses encontros.

\section{Referências}

BENJAMIN, W. O narrador. In: FIORI, O. Textos escolhidos. São Paulo: Abril Cultural, 1975. p.63-80

DELEUZE, G. Lógica do sentido. São Paulo: Perspectiva, 1998. Graal, 2006.

Diferença e repetição. Tradução de Luiz Orlandi, Roberto Machado. Rio de Janeiro:

Critica e Clínica. Trad. bras. Peter Pal Pelbart. São Paulo: Editora 34, 1997.

DELEUZE, G.; GUATTARI, F. O que é a filosofia? Trad. bras. Bento Prado Jr. e Alberto Alonso Muñoz. Rio de Janeiro: Editora 34, 1997.

GARCIA, A. V; GELAMO, R. P. Repensando o lugar da representação, da transmissão e da experiência no ensino da Filosofia. Filosofia e educação. Campinas, v. 4, n. 1, 2012.

GELAMO, R. P. O ensino da filosofia no limiar da contemporaneidade: o que faz o filósofo quando seu ofício é ser professor de filosofia? São Paulo: Cultura Acadêmica, 2009.

LARROSA, J. O ensaio e a escrita acadêmica. Educação e realidade. Porto Alegre, v. 28. n. 2, 2003.

RANCIÈRE, J. O mestre ignorante: Cinco lições sobre a emancipação intelectual. Trad. Lilian do Valle. Belo Horizonte: Autêntica, 2002.

\section{Notas}

${ }^{1}$ Cf. GARCIA; GELAMO, 2012.

${ }^{2}$ Cf. LARROSA, 2003; GELAMO, 2009.

${ }^{3} \mathrm{O}$ termo menor, aqui empregado, não designa um modo inferior ou algo de pouca qualidade. De acordo com o conceito desenvolvido por Deleuze e Guattari em Kafka por uma literatura menor (1977), podemos conceber por menor um modo de pensar que se constitui diferentemente daquele mantido sob jurisdição clássica da filosofia e das correntes teóricas majoritárias do pensamento ocidental.

${ }^{4}$ Como não acreditávamos ser possível estabelecer um objetivo a uma atividade que dissesse respeito a uma relação com pessoas que tiveram experiências singulares, propúnhamos que os adolescentes sugerissem 
situações temáticas que pudessem ser problematizadas ou repensadas. Faziam isso através da exposição de opiniões acerca de alguns questionamentos, tais como: a criminalidade se constitui no seio social ou por escolha própria? Qual é o elemento principal da felicidade humana? A violência policial se justifica? Existem diferenças entre estar privado de liberdade no regime fechado e no regime semiaberto? A liberdade existe realmente ou não? É possível ser livre mesmo estando privado de liberdade? Existem outras formas de expressão para além daquelas que conhecemos? O que é trabalho? A atividade criminosa pode ser considerda trabalho? O que é futuro e quais as expectativas sobre ele? Como agir em situações que abalam suas crenças? É possível que quem não tenha passado por um determinado problema ou situação possa entender aquele que passou ou tentar resolver o problema por essa pessoa?

${ }^{5}$ Entendemos como tematizações genuinamente filosóficas aquelas que dizem respeito a problemas constantemente investigados pelos filósofos, em grande medida no âmbito da Ética.

6 A noção de acontecimento que empregamos neste projeto precisa ser entendida não como um simples fato ocorrido, mas deve ser tratada como uma fissura que se abre no movimento de inércia, que insiste em habitar nosso pensamento violentando-nos com a força de um problema. Assim, o acontecimento funciona também como um signo, por si problemático e problematizante, que a todo momento nos dá a pensar, marcando intensamente nossa existência e nos impedindo de sermos indiferentes ao que aconteceu.

${ }^{7}$ Este modo de interrogação crítica e problematizadora de nossa atualidade, enquanto uma analítica do presente, é apresentado por Foucault como uma tarefa do filósofo: "[...] o que é a nossa atualidade? Qual é o campo atual das experiências possíveis? Não se trata aí e uma analítica da verdade, trata-se do que se poderia chamar uma ontologia do presente, uma ontologia de nós mesmos e parece-me que a escolha filosófica a qual nós nos encontramos confrontados atualmente é esta: pode-se optar por uma filosofia crítica que apresentará como uma filosofia da analítica da verdade em geral, ou pode-se optar por um pensamento crítico que tomará a forma de uma ontologia de nós mesmos, de uma ontologia da atualidade [...]” (FOUCAULT, 1984, p. 112).

* Mestranda pela Universidade Estadual Paulista Júlio de Mesquita Filho, Marília, São Paulo, Brasil.

** Mestranda pela Universidade Estadual Paulista Júlio de Mesquita Filho, Marília, São Paulo, Brasil.

*** Professor doutor da Universidade Estadual Paulista Júlio de Mesquita Filho, Marília, São Paulo, Brasil.

**** Mestranda pela Universidade Estadual Paulista Júlio de Mesquita Filho, Marília, São Paulo, Brasil.

$\star * \star * *$ Mestranda pela Universidade Estadual Paulista Júlio de Mesquita Filho, Marília, São Paulo, Brasil. 


\section{Correspondência}

Silmara Cristiane Pinto - Universidade Estadual Paulista Júlio de Mesquita Filho, Faculdade de Filosofia e Ciências - Campus de Marília. Av. Hygino Muzzi Filho, 737, Campus Universitário. CEP: 17525900. Marília, São Paulo - Brasil.

E-mail: silmaraffc@live.com - sara_moraesrosa@hotmail.com - gelamo@gmail.com - amanda.hipotenusa@gmail.com - manoelamenezes@hotmail.com

Recebido em 13 de outubro de 2014

Aprovado em 24 de março de 2015 